Periodica Polytechnica Mechanical Engineering, 66(2), pp. 137-143, 2022

\title{
Monitoring and Regulation of Indoor Conditions
}

\author{
Marinko Stojkov ${ }^{1 *}$, Krešimir Crnogorac², Tomislav Alinjak³, Bernarda Crnogorac ${ }^{4}$ \\ ${ }^{1}$ Faculty of Mechanical Engineering, University of Slavonski Brod, Trg Ivane Brlić Mažuranić 2a, 35000 Slavonski Brod, Croatia \\ 2 CONSTRUO-MAT d.o.o., Ignjata Alojza Brlica 4, 35000 Slavonski Brod, Croatia \\ ${ }^{3}$ HEP-DSO Zagreb, Elektra Slavonski Brod, Petra Krešimira IV 11, 35000 Slavonski Brod, Croatia \\ ${ }^{4}$ Faculty of Electrical Engineering, Computer Science and Information Technology, University of Osijek, Ul. Kneza Trpimira 2b, \\ 31000 Osijek, Croatia \\ * Corresponding author, e-mail: mstojkov@unisb.hr
}

Received: 24 October 2021, Accepted: 11 December 2021, Published online: 03 February 2022

\begin{abstract}
This paper presents research of energy performance analysis performed by Building Energy Management System (BEMS). BEMS is a system/platform integrated with building and it is an enormous improvement in a process to develop nearly zero energy buildings (nZEB). Near zero energy consumption stands for energy efficient idea of energy independent buildings for their function during their life time. Here, BEMS with function of monitoring and regulation of cooling energy demand is developed. BEMS regulates function of ventilation fan in area below tin roof and improves working conditions by inside building temperature reduction during summer period. Described technical solution is designed inside RESCUE IPA CBC project.
\end{abstract}

Keywords

BEMS, temperature, fan, ventilation, monitoring, regulation

\section{Introduction}

An important target according to EU directives on energy savings and energy efficiency is integration of BEMS inside the buildings. To gain self-sustainable energy building for living and function of smart cities, researchers should take care of basic indoor living parameters inside the new buildings, and also an improvement of living conditions inside existing buildings. Therefore, smart buildings need to be designed with contemporary technologies integrated in. Internet of Things, on-line continuous measurement monitoring and artificial intelligence regulation are only several of techniques which can be implemented. In the phase of design of a new building, it is relatively easy to apply previously mentioned techniques and technologies with some extra budget. A new question arises: how to solve this problem of BEMS integration in existing buildings. According to EU legislation, existing or new installed energy systems (heating, air-cooling, ventilation, lighting) inside the facilities needs to be integrated in BEMS to get modern controlled and regulated supervision with possibility to analyze archive data of energy consumption of each subsystem. The most important feature of implemented smart add-on systems should be its adaptability to different existing energy systems based on variety of equipment already installed with its specific requirements such as communication protocols. Also, there are practical problems and limitations connected to large number of building's users feed by separated energy systems (which have impacts/interaction to each other) or based on common energy subsystem (for example heating system) with some kind of applied energy distribution given either by measurement (better solution) or proportional to space ratio. BEMS integration approach based on new technologies and techniques is mandatory in energy redesign of existing buildings to satisfy energy efficiency requirements. Designing processes for zero-energy buildings or near zero-energy buildings focus on the reductions of energy demand or wider use of renewable energy sources that can increase energy efficiency. Control system and measuring proceeding of energy consumption and wide parameters of building's states/scenarios (such as windows and doors open/close, lighting on/off, window blinds (0-100\%), temperature, humidity, air quality (\% oxygen, $\mathrm{CO}_{2}$ ) and number of people that are present for each room/office) are very important. Building Energy Management Systems (BEMS) need to be created and integrated to cope with real-time measuring and building's 
states to which can be accessed remotely for example by mobile phone and also directing of building's subsystems can be also remotely performed.

Reduction of greenhouse gases emission is mankind target of great importance according to the Kyoto Protocol. Also, Renewable energy directive (2009/28/EC) promotes renewable energy sources in European Union [1]. Natural gas market with smart meters and intelligent metering systems are given by Directive 2009/73/EC [2]. Intelligent metering systems integration in new designed buildings and also improvement of old buildings in metering aspect are given by Energy Performance Building Directive (2010/31/EU) [3]. The potential of energy savings of existing and new-designed buildings according to their function is described in Directive (2010/31/EU). Old building renovation as great potential for reduction of energy consumption is main target of Energy Efficiency Directive (2012/27/EU) [4]. Energy Performance Building Directive (2018/844/EU) focus on the implementation of active control systems (building's measurement with data archiving, process automation, control of energy subsystems) and consequently on energy savings. An overview of nearly zero energy (nZEB) buildings standard application in Italy, Norway, Romania and Spain is given in [5]. Building Energy Management System (BEMS) integrated in housing for nearly zero energy buildings is described [6]. Also, energy efficiency models in nZEB are analyzed [7]. In Section 2, significance of indoor space parameters to secure health of occupants and preserve body comfort is analyzed. Section 3 of the paper deals with BEMS and improvement of energy subsystems managing, continually measuring and parameter data storing. In Section 4, new proposed BEMS for attic/roof space of faculty object's temperature regulation is described. At the end, conclusion analyzes results of the new designed ventilation subsystem and gives a number of new ideas for further research and integration of the ventilation subsystem inside the faculty object.

\section{Individual feeling indoor comfort parameters}

The technical challenge of great importance for engineers that should be continually improved is air quality inside the room/office to achieve healthy and pleasant environment for people to work, to research, to learn, to rest - all usually activities during the day. The air quality should be very similar at home, public institutions, industry and workshops' space except where technology process requires special conditions for example during painting or varnishing process (high temperature and relative overpressure) but with minimum time of men staying in special conditions (automatized processes). The working/learning effectiveness is preconditioned by suitable comfort. Also, long term care for workers health should be one of the most important targets of any company. Appropriate comfort depends on several parameters whose values should be in recommended range. Depending on type of men activity (industry, office, kitchen) and/or on subjective sense of comfort for an individual/person, some parameters needs to be adjustable. Nowadays, COVID-19 pandemic issue emphasizes importance of separate room ventilation with independent control system for each room to fulfil recommendations against spread of infection and to adapt indoor parameters to individual/person in specific room. Also, it is possible to turn off ventilation wherever is not needed (room without people) which enables energy savings and reduces chances for virus spreading through air circulation. Direct air room exchange with the outdoor air should be designed with considering energy savings during ventilation such as regeneration and recuperation methods.

The largest share of energy demand of a residual or public building is caused by heating/cooling subsystems. It is different inside industry because energy demand depends on working processes inside the factory. Basic precondition of appropriate comfort is room temperature which is regulated by heating or cooling subsystem. At the other hand, energy demand of ventilation subsystem is neglected in comparison to heating/cooling subsystems, but it can produce large energy losses during its function in case of unprofessional design. Usually, it is not problem at all in new buildings, but for present buildings it is an important problem to solve. To optimize indoor parameters in the whole building, observation for each room and space of the building is performed separately considering work efficiency, individual comfort, number of people in specific room, unused rooms (without people) and energy savings.

Beside the temperature, other important indoor parameters are light level, air quality (concentration of $\mathrm{CO}_{2}, \mathrm{O}_{2}$, $\mathrm{CO}, \mathrm{PM}$ particles, dust), humidity, even noise level. So, comfort indoor parameters for people to live and work are as following: air temperature in range $20-22{ }^{\circ} \mathrm{C}$; relative humidity in range $40 \%-60 \%$; air flow velocity less than $0.15 \mathrm{~m} / \mathrm{s}$ (maximum $0.25 \mathrm{~m} / \mathrm{s}$ ); minimum oxygen content $19.5-20 \%$; minimum number of air changes: $1-3 \mathrm{~h}^{-1}$ (which depends on the number of people). In case humidity is lower than $40 \%$, the sense of air dryness and also the movement of micro particles inside can be irritating. 
In opposite, in case relative humidity is higher than $60 \%$, people often start to sweat. To avoid high humidity problem, heating subsystem need to boost the temperature by $1-2 \%$ or humidity reduction need to be done by ventilation subsystem if outdoor conditions are suitable. The maximum difference of air room temperature and walls surface temperature during the summer need to be in the range $1-3{ }^{\circ} \mathrm{C}$. Naturally the room air temperature changes as a function of the outdoor temperature but the maximum difference of air temperatures during the day need to be in range $4-7{ }^{\circ} \mathrm{C}$. The maximum difference of air room temperature and walls surface temperature during the winter need to be in range $2-4{ }^{\circ} \mathrm{C}$, but the relative inside humidity need to be on lower level than is the condensation value at a certain temperature.

\section{Integration of BEMS}

The authors describe in details BEMS-SR (Building Energy Management System - Smart Room) with its function to continually regulate and measure indoor parameters, momentary load and energy consumption during selected time period of heating subsystem, cooling subsystem, ventilation subsystem, humidity regulation subsystem and lighting installation in the building. Regulation should be designed by integration of technical devices (measurement sensors, controllers and actuators) and suitable software based on fuzzy logic and artificial intelligence to get optimal energy savings. Described BEMS-SR present smart room as a part of concept of smart buildings, and wider as a part of concept of smart cities. Central master level of BEMS takes, archives, and analyzes all data for each room and control central heating system, but the regulation process of living parameters is delegated to BEMS-SR independently. Indoor parameters are monitored and archived on cloud platform which enable their verifying in comparison to outdoor parameters for each room in the building (living parameters, occupancy or number of people in specific room, energy needs etc.), on specific floor (wing or part of the building) according to room assignment or total energy demand integrated for whole building. Measurement sensors installed in specific room continually monitor temperature, $\mathrm{O}_{2}$ concentration, $\mathrm{CO}_{2}$ and $\mathrm{CO}$ concentration, humidity, energy consumption of each subsystem installed in the room. Control system regulates each measured parameter to be inside recommended range or defined by user, all in a real-time. BEMS-SB controls common heating system, measures and stores the data. Described intelligent building energy management systems enable predictive and automated decisions simultaneously reducing energy consumption and improving user's health conditions and comfort parameters. Also, BEMS-B could be connected to fire protection system and to protection of unauthorized entry in the object. So, smart buildings take care of user's comfort (tenants, workers) by optimizing indoor lighting, by achieving predefined temperature and humidity, by ensuring optimal amount of fresh, and also by accomplishing energy savings and security of persons and building itself. These adjustable indoor parameters of user's comfort could be inside predefined range or customized for specific room inside the building no matter is it located on the sunny side or on shade side of the object, no matter of insulation mounted on the walls etc. BEMS-SR has modular structure, consisted of different sensors (light, temperature, air quality, particles, counter of present persons, energy counters, fire (smoke) sensors etc.), actuators and control system which can be added depending on user's needs. The processor has intelligent and adaptable control software. That software code is programmable and in modular structure what enable temporary or permanent isolation of unnecessary parts of the code by selection of offered options. Measured data are sent to BEMS-SB centralized monitoring cloud platform that enables connection with artificial intelligence tools for data analysis and working in sync via the Internet of Things (IoT) technology.

\section{Experimental procedure}

Analyzed building 2 of University of Slavonski Brod is built in 1962 and there is no modern thermal isolation of the walls. The building has ribbed tin roof also without thermal isolation. The attic area of the building has surface of $701 \mathrm{~m}^{2}$. Temperatures during summer in attic area reach up to $53{ }^{\circ} \mathrm{C}$ what reflects on temperatures on the first floor (under the attic area). There is not cooling system installed in the object except in computing classrooms. Also, thermal energy losses during winter consequently are very notable.

Installed BEMS-R monitor outdoor temperature and indoor temperature of the attic area of the building, measured data are sent into local processor which has several functions: to compare outdoor and indoor temperatures, to wirelessly send data to TELMATIKS remote central cloud platform. The IoT $^{\mathrm{TM}}$ Platform is designed on the highest standards of security which has ISO 27001 compliance confirmed by authorized third party-firm. Control code can be performed locally and in a cloud environment, depending on the security level of customer's needs. Special care is dedicated to data/functions integrity/security 
by implementing ISO 27001 Information security management system (ISMS) according to the international standard in small and medium enterprises (SMEs) [8].

Measurement sensors installed in the project are digital type with three wires, 9-12 bits of Celsius measurements resolution, in range $-55^{\circ} \mathrm{C}$ to $+125^{\circ} \mathrm{C}$. Measurement accuracy is $0.5^{\circ} \mathrm{C}$ in range $-10^{\circ} \mathrm{C}$ to $+85^{\circ} \mathrm{C}$. Sensors needs 3-5 V DC as power supply. The sensor's dimensions are typical $5 \times 5 \mathrm{~mm}$. Each sensor has its unique 64-bit serial code (address) to enable connection of several sensors for multiple measurements on control system. Used measurement sensor is ideal for HVAC system, different measurements inside the building or inside the factory/offices) to enable simple, low power, good precision, wide temperature range, low power consumption, small dimensions and multiple measurements point (type of sensor: DS18B20) [9].

Control unit, communication unit and power supply unit are integrated in one housing (typical dimensions of $50 \times 30 \mathrm{~mm}$ ). Control unit - RASPBERRY has 32-bit RISC processor, 16 digital inputs/outputs, 1 analog input, $4 \mathrm{MB}$ of flash memory, $128 \mathrm{kB}$ SRAM, speed clock is $80-160 \mathrm{MHz}$. Control unit has operating voltage $3.3 \mathrm{~V}$ and typical operating current is under $100 \mathrm{~mA}$. It is equipped with UART/SIPS/I2Cs communication interfaces. Also, it has deep sleep function with typical operating current of $60 \mu \mathrm{A}[10,11]$. WiFi transmitter including antenna is connected to control unit and power supply unit. It enables easy wireless communication and integration in existing building installation, or it can be connected via ethernet port. Also, further implementation of any system upgrades is possible with available capacity of modern electronic devices. Communication unit is ideal for long term application and it is also simple to implement IoT/AI building automation projects. Similar measurement process is described in [12] for heat pump modelling and in [13] for compressor station regulation.

During the night period, air inside roof/attic is partially changed (as the first phase of pilot project) by forced variable ventilation (electrical motor with ventilation fan) with outdoor air. During the day period, in case of the inside temperature of attic air is greater than $22{ }^{\circ} \mathrm{C}$ and the temperature difference between inside and outside air temperature are greater than $2.5^{\circ} \mathrm{C}$, control system starts its actuator - electrical ventilation fan. In the summer time during the day, attic air becomes very hot (maximum measured temperature is $53.12{ }^{\circ} \mathrm{C}$ ) thus raising temperature at the first floor of the object where maximum temperature at the south orientation classroom is $36^{\circ} \mathrm{C}$. It is very bad working condition either for administration in offices, or for research in laboratories or for lectures with students. To get actual temperatures of specific room in the object, BEMS-SR is installed with 12 temperature sensors that continually measure, store and send on-line temperature data to centralized cloud platform. Control device for internal parameters monitoring is presented in Fig. 1. Here, measurement of temperature, humidity and PM data are processed.

Rotation speed of the fan electric motor is regulated by frequency regulation to get variable motor speed drive and variable volume flow of air circulation and to optimize energy consumption. Proposed ventilation system as part of BEMS-SB is in function only one year and BEMS-SR is in function for 16 months (planned research project period is 36 months), so measured data to analyze are available but long enough projected time period is need to get objective results for further research analyze. By function of described BEMS and local ventilation system of attic area, it is expected to enable better living and working comfort parameters in the building by decreasing air temperature at the first and ground floor of the university building.

Graph presented in Fig. 2 (without function of ventilation system) shows that in certain periods temperatures of the air below roof was up to $+53.12{ }^{\circ} \mathrm{C}$ during the day (blue line) while outside maximum temperature during day period was up to $+46.25{ }^{\circ} \mathrm{C}$ (red line). During night period, minimum temperatures below roof were down to $+24.25{ }^{\circ} \mathrm{C}$ (Fig. 2), while outside minimum temperatures during night period were in range up to $+17.35{ }^{\circ} \mathrm{C}$ (red line). Practically all the time during the summer period temperature of the air under the roof was higher than

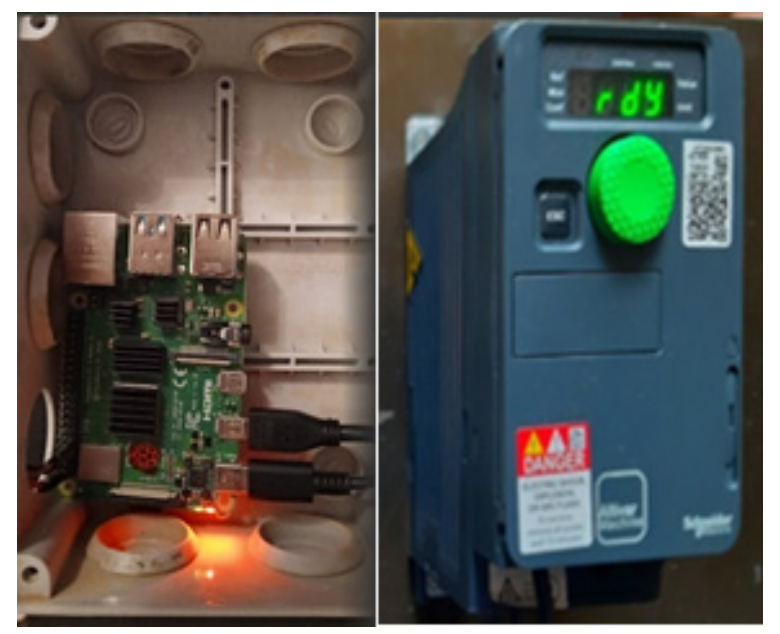

Fig. 1 Control unit, communication unit, power supply (left) and motor/ fan frequency/RPM regulating unit/variable frequency drive for motor/fan (right) 


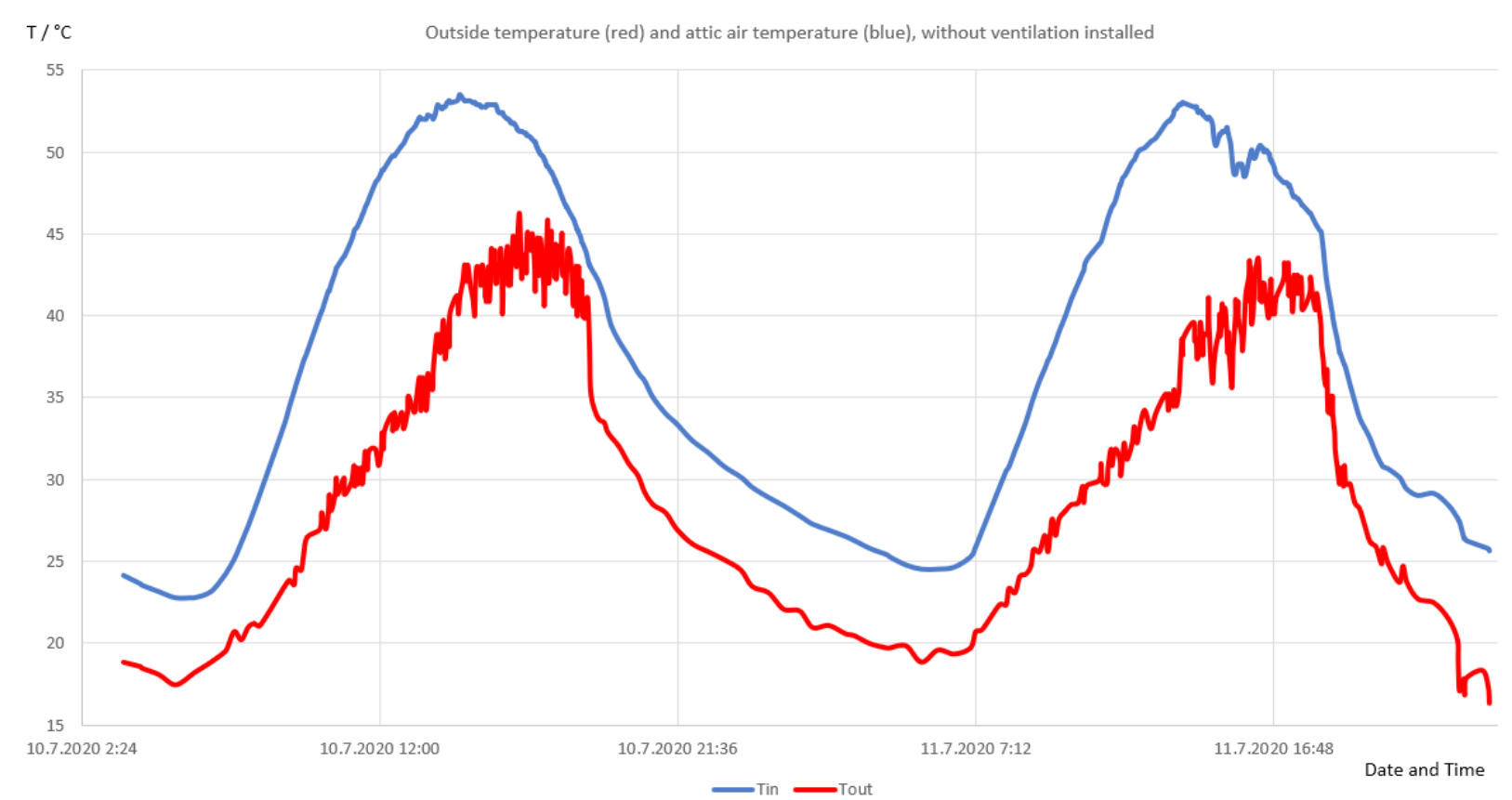

Fig. 2 Temperature monitoring of the attic air during two consecutive summer days in July of 2020, without BEMS and ventilation system

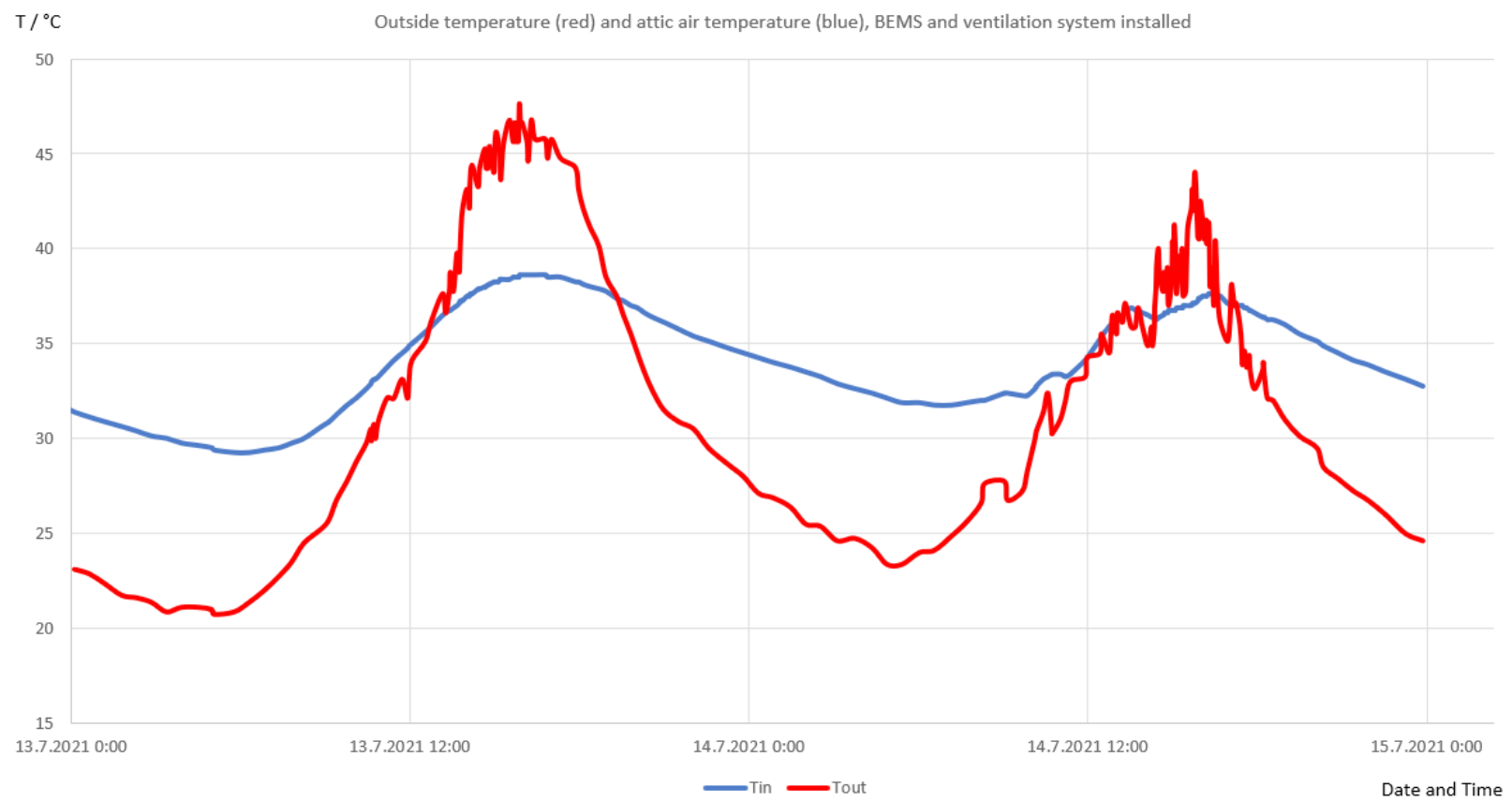

Fig. 3 Temperature monitoring of the attic air during two consecutive summer days in July of 2021, with BEMS and ventilation system

outside air temperature caused by the tin roof (as a solar collector) without thermal isolation and restricted volume without air change potential.

Graph presented in Fig. 3 (with function of BEMS and ventilation system) shows that the maximum temperature of the air below roof were $+38.6{ }^{\circ} \mathrm{C}$ (blue line), while outside maximum temperature during day period was $+47.62{ }^{\circ} \mathrm{C}$ (red line). During the night period, temperatures below roof were in range $+29.25^{\circ} \mathrm{C}$ up to $+31.75^{\circ} \mathrm{C}$ (Fig. 3), while outside temperatures during night period were in range $+20.75{ }^{\circ} \mathrm{C}$ up to $+23.38{ }^{\circ} \mathrm{C}$ (red line). The temperatures of analyzed two consecutive days in July 2021 can be compared by temperatures of chosen two consecutive days in July 2020 because maximum outdoor air temperatures are pretty similar $\left(+46.25^{\circ} \mathrm{C}\right.$ in 2020 and $+47.62{ }^{\circ} \mathrm{C}$ in 2021) and also minimum outdoor temperatures are similar $\left(+16.38^{\circ} \mathrm{C}\right.$ up to $+17.35^{\circ} \mathrm{C}$ in 2020 and $+20.75^{\circ} \mathrm{C}$ up to $+23.38{ }^{\circ} \mathrm{C}$ in 2021). Although outdoor air temperatures in 
July of 2021 determined harder working conditions, results of the function of BEMS-R and ventilation system (Fig. 4; Fig. 5) is clear to see: attic air temperature were $+38.6{ }^{\circ} \mathrm{C}$ in 2021 in comparison to $53.12{ }^{\circ} \mathrm{C}$ in 2020 .

Control unit monitors temperature measurement and sends measurement data to the cloud memory (Fig. 6). Developed TELMATIKS platform is developed as multipurpose physical parameters measurement and is serviceable for modification depending on end-user needs, it can be custom-made; for example, measurement sampling resolution, maximum values, minimum values and average values of measured physical parameters during monitored interval. Telmatiks communication with control unit is enabled either by WiFi network or GSM network.

If attic area has partially, or even better full exchange, of inside air by forced ventilation during night period with outside lower temperature air, interesting drop of inside air temperatures are expected during the day period. It has reflection on inside air temperatures in working areas of building (ground floor and first floor). Rated electrical power of used fan in ventilation system is $340 \mathrm{~W}$. It is planned to use fan several hours during night in period when electrical energy tariff is cheaper.

In praxis, it is obvious that only one ventilation fan is not sufficient (which was given earlier by calculation according to volume flow of the fan and volume of the attic area) because indoor air temperature is still greater than outdoor night air temperature (there is no full change of air volume). To achieve better results three fan units should be mounted along the analyzed building. In performed real experiment, it is clear that described system enables reduction of energy consumption for air conditioning units' function, costs of energy consummated are also reduced and also $\mathrm{CO}_{2}$ emissions are reduced. The air under the roof will have lower temperature, very close to outside night air

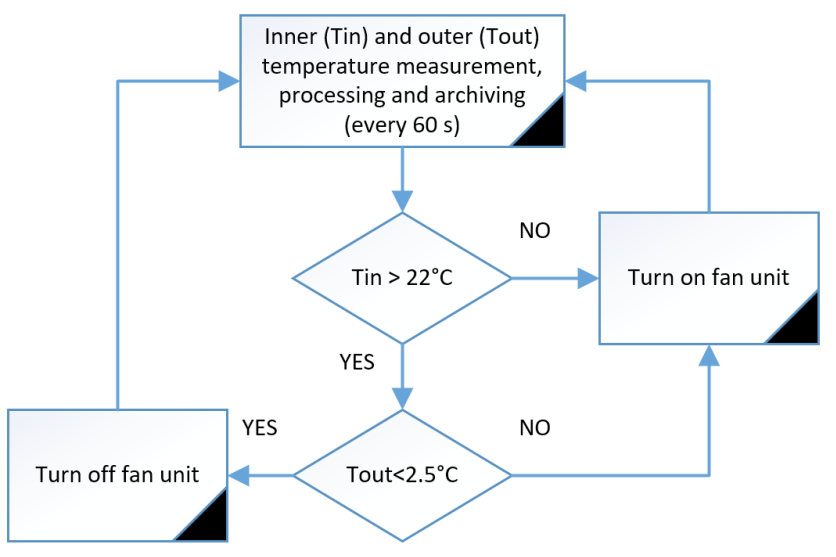

Fig. 4 Flow chart of the BEMS-R and smart ventilation system temperatures, heat transfer from the attic area to classrooms below attic area is reduced and also duration of air conditioning systems running time are reduced. Finally, and also very important, working conditions during lectures and laboratory research will also be more pleasant and healthier.

\section{Conclusions}

The best way to verify our assumptions and model calculations is to apply BEMS-R and ventilation system on real object, to perform continually measurements and compare obtained data with the expected results. Paper describes function of BEMS-R installed in attic area of the Mechanical Engineering Faculty building in Slavonski Brod, its advantages and control system for ventilation of the under-roof area. Developed smart ventilation system is expected to improve working conditions by inside building temperature reduction during summer period. Simultaneously, some energy savings are reached. Described system is in function for 16 months (almost a half of the planned period), but there are interesting results enabling energy efficiency and working conditions with very modest financial investment. Further research will be focused on improvements of the system for example defining optimum number and location of fan units and rated power (volume flow) of fan units.

\section{Acknowledgement}

This research is supported by Renewable Energy Sources for smart sustainable health Centers, University Education and other public buildings (RESCUE) IPA CBC project with Faculty of Technical Science Novi Sad as a leading partner, Faculty of Electrical Engineering, Computer Science and Information Technology Osijek, Mechanical Engineering Faculty in Slavonski Brod, Clinical Center of Vojvodina and Clinical-Hospital Center Osijek as partners. Also, Construo-mat gives enormous support in equipment during development and design of this project.

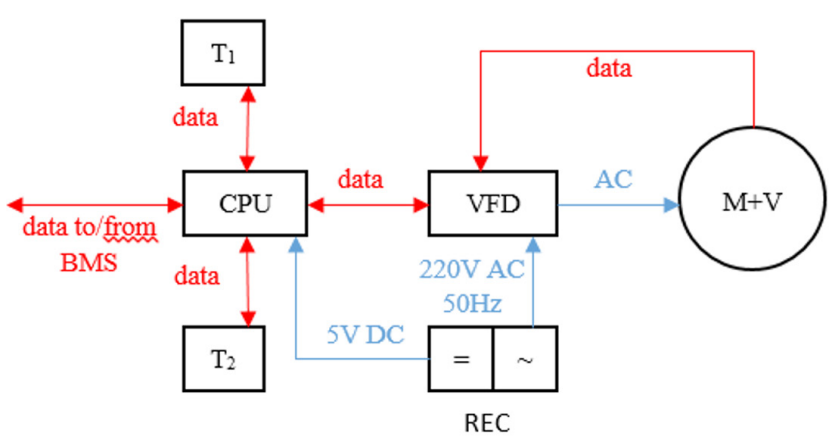

Fig. 5 Block diagram of the BEMS-R and smart ventilation system (CPU - control module, T1 and T2 - temperature probes, VFD - motor inverter, $\mathrm{REC}-$ rectifier, $\mathrm{M}+\mathrm{V}-$ motor with cooling fan 


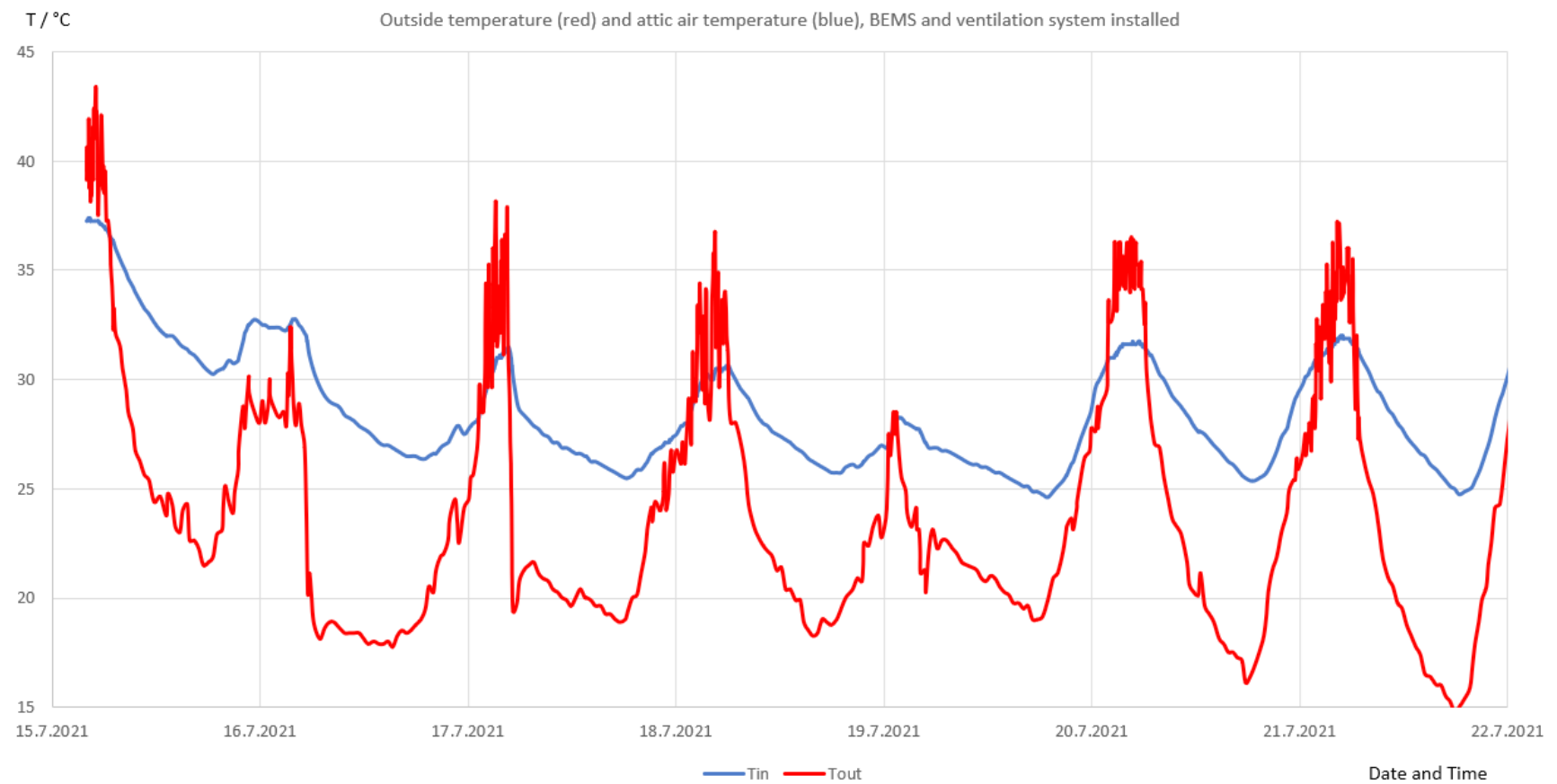

Fig. 6 Measured air temperatures during 7 days- archived on the cloud memory

\section{References}

[1] EU "Directive 2009/28/EC of the European Parliament and of the Council of 23 April 2009 on the promotion of the use of energy from renewable sources and amending and subsequently repealing Directives 2001/77/EC and 2003/30/EC", Official Journal of the European Union, L 140/16, pp. 16-62, 2009.

[2] EU "Directive 2009/73/EC of the European Parliament and of the Council of 13 July 2009 concerning common rules for the internal market in natural gas and repealing Directive 2003/55/EC", Official Journal of the European Union, L 211/94, pp. 94-136, 2009.

[3] EU "Directive 2010/31/EU of the European Parliament and of the Council of 19 May 2010 on the energy performance of buildings", Official Journal of the European Union, L 153/13, pp. 13-35, 2010.

[4] EU "Directive 2012/27/EU of the European Parliament and of the Council of 25 October 2012 on energy efficiency, amending Directives 2009/125/EC and 2010/30/EU and repealing Directives 2004/8/EC and 2006/32/EC", Official Journal of the European Union, L 315/1, pp. 1-56, 2012.

[5] Bointner, R., Toleikyte, A., Kranzl, L. "Cross-country analysis of the implementation of nearly zero-energy building standards across Europe", In: 2nd International Conference on Intelligent Green Building and Smart Grid (IGBSG), Prague, Czech Republic, 2016, pp. 1-6.

https://doi.org/10.1109/igbsg.2016.7539424

[6] Maask, V., Rosin, A., Roasto, I. "Development of Experimental Load Management System for Nearly Zero-Energy Building", In: IEEE 59th International Scientific Conference on Power and Electrical Engineering of Riga Technical University (RTUCON), Riga, Latvia, 2018, pp. 1-5.

https://doi.org/10.1109/RTUCON.2018.8659826
[7] Mademlis, C. "A Holistic Approach for Increasing the Electric Energy Efficiency of a Nearly Zero Energy Building", In: 5th International Symposium on Environment-Friendly Energies and Applications (EFEA), Rome, Italy, 2018, pp. 1-6. https://doi.org/10.1109/EFEA.2018.8617064

[8] ISO "ISO/IEC 27001 Information Security Management", [online] Available at: https://www.iso.org/isoiec-27001-informationsecurity.html [Accessed: 06 August 2021]

[9] Maxim Integrated "DS18B20 Programmable Resolution 1-Wire Digital Thermometer", [online] Available at: https://datasheets. maximintegrated.com/en/ds/DS18B20.pdf [Accessed: 06 August 2021]

[10] ESPRESSIF "ESP8266A cost-effective and highly integrated Wi-Fi MCU for IoT applications", [online] Available at: https://www. espressif.com/en/products/socs/esp8266/[Accessed:06August2021]

[11] ESPRESSIF "ESP8266EX Datasheet, Version 5.2", [pdf] Available at: https://www.taydaelectronics.com/datasheets/files/A-2194.pdf [Accessed: 06 August 2021]

[12] Sánta, R., Garbai, L. Furstner, I. "Numerical investigation of the heat pump system", Journal of Thermal Analysis and Calorimetry, 130, pp. 1133-1144, 2017. https://doi.org/10.1007/s10973-017-6489-8

[13] Đuračić, I., Stojkov, M., Šarić, T., Alinjak, T., Crnogorac, K. "Applying Artificial Neural Network to Optimize the Performance of the Compressor Station: A Case Study", Tehnički vjesnik, 28(4), pp. 1197-1202, 2021. https://doi.org/10.17559/TV-20200926113750 